\title{
Neuromuscular, Endocrine, and Perceptual Fatigue Responses During Different Length Between-Match Microcycles in Professional Rugby League Players
}

\author{
Blake D. McLean, Aaron J. Coutts, Vince Kelly, \\ Michael R. McGuigan, and Stuart J. Cormack
}

\begin{abstract}
Introduction: The purpose of this study was to examine the changes in neuromuscular, perceptual and hormonal measures following professional rugby league matches during different length between-match microcycles. Methods: Twelve professional rugby league players from the same team were assessed for changes in countermovement jump (CMJ) performance (flight time and relative power), perceptual responses (fatigue, well-being and muscle soreness) and salivary hormone (testosterone $[\mathrm{T}]$ and cortisol $[\mathrm{C}]$ ) levels during 5, 7 and $9 \mathrm{~d}$ between-match training microcycles. All training was prescribed by the club coaches and was monitored using the session-RPE method. Results: Lower mean daily training load was completed on the $5 \mathrm{~d}$ compared with the 7 and $9 \mathrm{~d}$ microcycles. CMJ flight time and relative power, perception of fatigue, overall well-being and muscle soreness were significantly reduced in the $48 \mathrm{~h}$ following the match in each microcycle $(P$ $<.05)$. Most CMJ variables returned to near baseline values following $4 \mathrm{~d}$ in each microcycle. Countermovement jump relative power was lower in the $7 \mathrm{~d}$ microcycle in comparison with the $9 \mathrm{~d}$ microcycle $(P<.05)$. There was increased fatigue at $48 \mathrm{~h}$ in the 7 and $9 \mathrm{~d}$ microcycles $(P<.05)$ but had returned to baseline in the $5 \mathrm{~d}$ microcycle. Salivary T and C did not change in response to the match. Discussion: Neuromuscular performance and perception of fatigue are reduced for at least 48 $\mathrm{h}$ following a rugby league match but can be recovered to baseline levels within $4 \mathrm{~d}$. These findings show that with appropriate training, it is possible to recover neuromuscular and perceptual measures within $4 \mathrm{~d}$ after a rugby league match.
\end{abstract}

Keywords: neuromuscular fatigue, testosterone, cortisol, team sport, monitoring

\footnotetext{
Blake D. McLean is with the School of Leisure, Sport and Tourism, University of Technology, Sydney, Lindfield, New South Wales, Australia, and with the South Sydney Rugby League Football Club, Redfern, New South Wales, Australia. Aaron J. Coutts is with the School of Leisure, Sport and Tourism, University of Technology, Sydney, Lindfield, New South Wales, Australia. Vince Kelly is with the South Sydney Rugby League Football Club, Redfern, New South Wales, Australia, and with the School of Human Movement Studies, University of Queensland, St Lucia, Queensland, Australia. Michael R. McGuigan is with the New Zealand Academy of Sport, Auckland, New Zealand and with the Auckland University of Technology, Auckland, New Zealand. Stuart J. Cormack is with the Essendon Football Club, Essendon, Victoria, Australia.
} 
It is well established that professional athletes need to train at high-intensity to elicit improvements in skill and all qualities of physical fitness relating to that particular sport, ${ }^{1}$ it is also understood that too much high-intensity training, without adequate recovery periods, will have a detrimental effect on performance. ${ }^{2}$ However, there is still relatively little research that has examined the efficacy of methods for monitoring player fatigue and recovery, especially in high performance team sport athletes. ${ }^{3-10}$ An accumulation of fatigue or incomplete recovery can have a large influence on performance, especially during periods of regular competition. If player fatigue and recovery is not managed appropriately, team sport athletes may be at greater risk of underperformance.

Professional rugby league is played on a regular week to week basis, over a long season, and it can be difficult to balance appropriate training and recovery strategies. ${ }^{11}$ Although it has been identified that monitoring levels of fatigue is important, there is currently limited research examining the most appropriate methods to do this in professional rugby league players. The only available research relating to fatigue in rugby league has examined deliberately overreached athletes. ${ }^{3,6,12}$ Coutts et $\mathrm{al}^{6}$ reported significant reductions in aerobic capacity and hamstring torque in 7 semiprofessional rugby league players after $6 \mathrm{wk}$ of progressive overload training with limited recovery periods. However, no investigations have examined how team sport athletes react to differing length in-season microcycles.

A number of nonfatiguing performance measures and biochemical markers are suggested to be useful in regular monitoring team sport athletes. ${ }^{5,7}$ These measures have been shown to be effective in detecting fatigue in deliberately overreached athletes. ${ }^{6,12,13}$ Coutts et $\mathrm{al}^{13}$ found a $7.9 \%$ decrease in five bound horizontal jump test for distance and an increase in stress reaction symptoms after 4 wk of intensified training in sixteen male triathletes. There are however, relatively few studies examining the usefulness of these measures during a team sport season when athletes are not deliberately overreached, but may be experiencing symptoms associated with the early stages of overreaching. ${ }^{5,714-16}$ Early detection of these subtle symptoms may allow coaches to intervene and avoid the detrimental effects associated with maladaptive training.

Therefore, the purpose of this research was to examine the changes in neuromuscular fatigue, perceptual fatigue and salivary hormones in professional rugby league players during the in-season period. A further aim of this study was to examine differences in these fatigue measures during different length recovery periods between matches.

\section{Methods}

\section{Subjects}

Twelve professional rugby league players (age: $24.3 \pm 3.6$ y, body mass: $101.9 \pm 8.4$ $\mathrm{kg}$, stature: $184.7 \pm 6.1 \mathrm{~cm}$, sum of 7 skinfolds: $66.0 \pm 12.0 \mathrm{~mm}$, playing experience: $69 \pm 65$ National Rugby League [NRL] matches) representing the South Sydney Rabbitohs NRL team volunteered to participate in this study. All subjects were given a verbal and written description of the procedures and possible risks before participation. Each subject completed a voluntary written consent form and the study was approved by a university human ethics review panel. 


\section{Research Design}

This study examined the neuromuscular, endocrine and perceptual fatigue responses during three different duration training weeks throughout a 26 wk rugby league season. Subjects were familiarized with all experimental protocols before the commencement of the study period. The three experimental weeks consisted of $5 \mathrm{~d}, 7 \mathrm{~d}$ and $9 \mathrm{~d}$ between-match periods. Experimental weeks were completed at weeks 3, 7 and 18 of the 2008 NRL season for the 9,5 and $7 \mathrm{~d}$ recovery periods respectively. All 12 subjects were assessed in each microcycle.

\section{Performance Measures}

Baseline countermovement jumps (CMJ) were examined at the end of a preseason taper period. The timing of these measures was selected as the training load had been reduced to recover the players before competition. These CMJ values were then compared with CMJ performance $1 \mathrm{~d}$ postmatch, $4 \mathrm{~d}$ postmatch and the day before the following match (for 7 and $9 \mathrm{~d}$ experimental weeks only). All CMJs were completed at a standard time between 8:00 to 10:00, before commencing training. Before beginning the CMJs, subjects performed a standardized 5 min dynamic warmup, similar to that previously described. ${ }^{8}$ This warm-up used a number of different running patterns at increasing intensity and dynamic stretches followed by three submaximal practice jumps. The players then performed a single CMJ. The CMJs were performed with hands held firmly on the hips and subjects were instructed to jump as high as possible. All jumps were performed at a self-selected countermovement depth and no instruction was given on what countermovement depth to use.

All CMJs were performed on a force plate (400 Series Performance Plate, Fitness Technology, Adelaide, Australia) connected to a computer running software (Ballistic Measurement System, Fitness Technology, Adelaide, Australia) that recorded vertical ground reaction forces at $200 \mathrm{~Hz}$. Relative Power (CMJRelP) and Flight time (CMJFT) of each jump was assessed using custom-designed software, capable of automatically detecting these variables (Mathworks, Natick, Massachusetts, USA). These CMJ variables have previously ${ }^{5,7,8}$ been described and have been shown to be reliable ${ }^{8}$ and useful in detecting low frequency fatigue in team sport athletes. ${ }^{5,7}$ Subjective feelings offatigue: During the study period athletes completed a custom-made psychological questionnaire that was based on the recommendations of Hooper et al. ${ }^{17}$ The questionnaire assessed their fatigue, sleep quality, general muscle soreness, stress levels and mood on a five-point scale (scores of 1 to 5, 0.5 point increments; see Figure 1). Overall well-being was then determined by summing the five scores. The well-being questionnaire (WB) was completed $4 \mathrm{~h}$ before the first match, and then $1,2,4,5^{*}, 6^{*}, 7^{*}, 8^{*}$ and $9^{*} \mathrm{~d}$ following (*depending on microcycle). The well-being questionnaires were completed immediately after giving the saliva sample at the prescribed time (8:00 or 11:00) on experimental days.

\section{Physiological Measures}

Endocrine responses to matches and training were measured through salivary analysis. Saliva collection involved players passively drooling directly into a 20 $\mathrm{mL}$ plastic tube (Model SCP5014GL, Bacto Laboratories, Mt Pritchard, Australia). Samples were then sealed with a plastic screw-top lid and frozen at $-20^{\circ} \mathrm{C}$ 


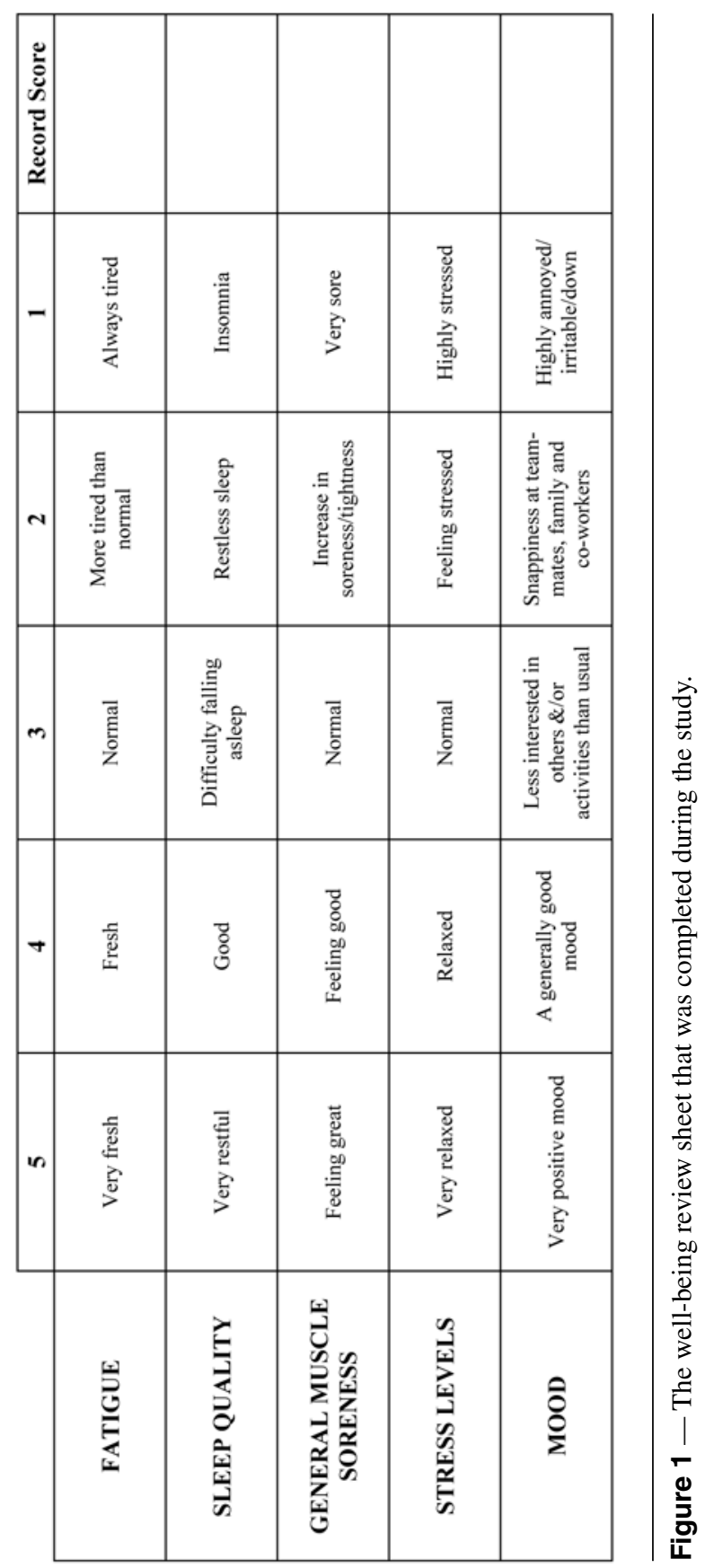


until analysis. Athletes were asked to maintain their normal diet throughout the study period and ingest only water $30 \mathrm{~min}$ before providing the saliva sample. Saliva samples were collected from the players 4 h prematch and $1 \mathrm{~d}, 2 \mathrm{~d}$, and $4 \mathrm{~d}$ postmatch in all three experimental weeks. Sample collection after $4 \mathrm{~d}$ postmatch varied depending on the experimental week. Sample collection times on the three experimental weeks are shown in Figure 2. All saliva samples were collected at 08:00 to keep diurnal variations constant at the time of collection; this is with the exception of samples collected on match days. All samples collected on match days were collected at 11:00 as to not disrupt athletes sleeping patterns on match day. Therefore it is possible that changes in timing of saliva sample collection on match day may have influenced these hormonal measures as the release of testosterone
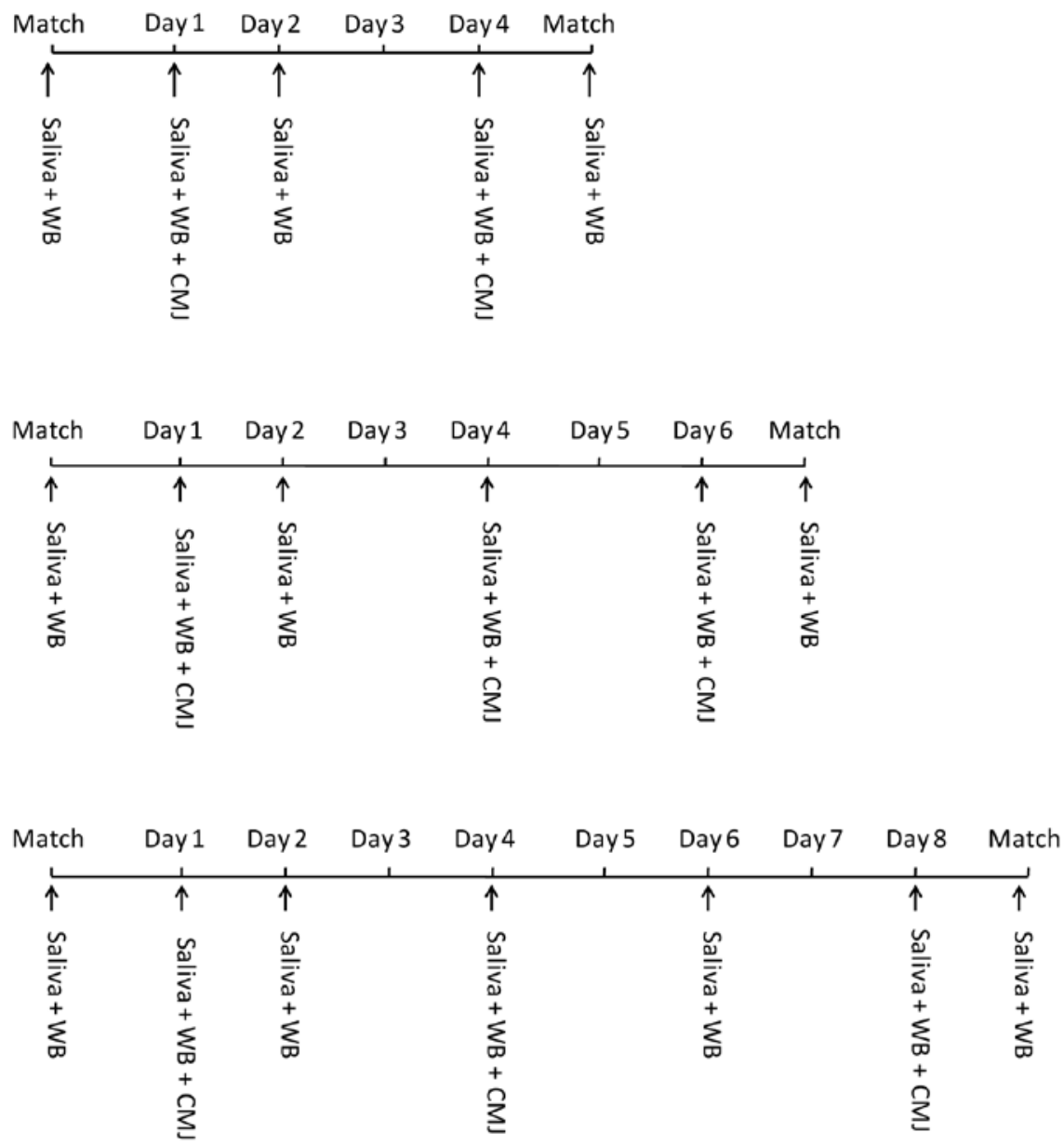

Figure 2 - Data collection timeline for the $5 \mathrm{~d}, 7 \mathrm{~d}$ and $9 \mathrm{~d}$ microcycles. $\mathrm{CMJ}=$ countermovement jump, $\mathrm{WB}=$ well-being questionnaire. 
and cortisol is affected by circadian rhythm. All samples were analyzed together upon the completion of the experimental period to minimize intra-assay variability.

Cortisol $(\mathrm{mg} / \mathrm{dL})$ and testosterone $(\mathrm{pg} / \mathrm{mL})$ were determined in duplicate by enzyme-linked immunosorbent assay (Salimetrics, PA, USA) using a microplate reader (SpectraMax 190, Molecular Devices, CA, USA). The coefficient of variation as a percent of the assays was $7.3 \%$ and $2.4 \%$ for testosterone and cortisol, respectively.

\section{Physical Training}

All participants took part in normal team training, prescribed by coaches and strength and conditioning staff. Training was not altered in any way for the purposes of this study. Table 1 provides a general description of the training content completed in each microcycle. The training loads for each experimental week were recorded using methods described by Foster et al. ${ }^{9}$ This method calculates a total training load (arbitrary units [AU]) by multiplying the session-RPE by the session time.

\section{Statistical Analyses}

To eliminate the variation of individual patterns and fluctuations of all measures (performance, psychological and hormonal), all raw data were converted to a Z-score calculated for each individual player before analyses. A Z-score expresses a score in terms of the number of standard deviation units the raw score is below or above the mean of the distribution and is calculated using the following formula: (individual players score-individual players average)/individual players standard deviation (SD). The Z-scores for CMJ variables, cortisol and testosterone were calculated using all data points collected from each player over the study period, including baseline measures. As the same perceptual measures had been recorded extensively in this group of athletes before the study commencing, perceptual fatigue Z-scores were calculated from all available data for each player, this ranged from six months to two years of baseline data. A two-way univariate ANOVA was used to examine main effects for microcycle $(5 \mathrm{~d}, 7 \mathrm{~d}$ and $9 \mathrm{~d})$ and time (time course changes). Within (time course changes) and between microcycle ( $5 \mathrm{~d}, 7 \mathrm{~d}$ and $9 \mathrm{~d}$ ) post hoc analysis and training load measures were analyzed using one-way ANOVA. Effect size (ES) statistics were calculated using Cohen's $d$ and eta squared $\left(\eta^{2}\right)$ statistics. Values of $0.2,0.5$ and $>0.8$ were considered small, moderate and large, respectively. An alpha (a) level of $<0.05$ was used as the criterion for significance. Statistical analyses were performed using the software package SPSS (version 15.0). All data are mean \pm SD.

\section{Results}

Figure 3A shows mean $( \pm \mathrm{SD}$ ) relative daily training load performed in each of the different microcycles. Significantly higher mean daily load was found in the $7 \mathrm{~d}(P$ $<.05, d=0.45)$ and $9 \mathrm{~d}(P<.01, d=0.59)$ microcycles when compared with the $5 \mathrm{~d}$ microcycle. Figure $3 \mathrm{~B}$ shows mean $( \pm \mathrm{SD})$ overall training load performed in each of the different experimental microcycles. A higher overall training load was found in the $9 \mathrm{~d}$ microcycle when compared with the $5 \mathrm{~d}(P<.001, d=0.95)$ and 


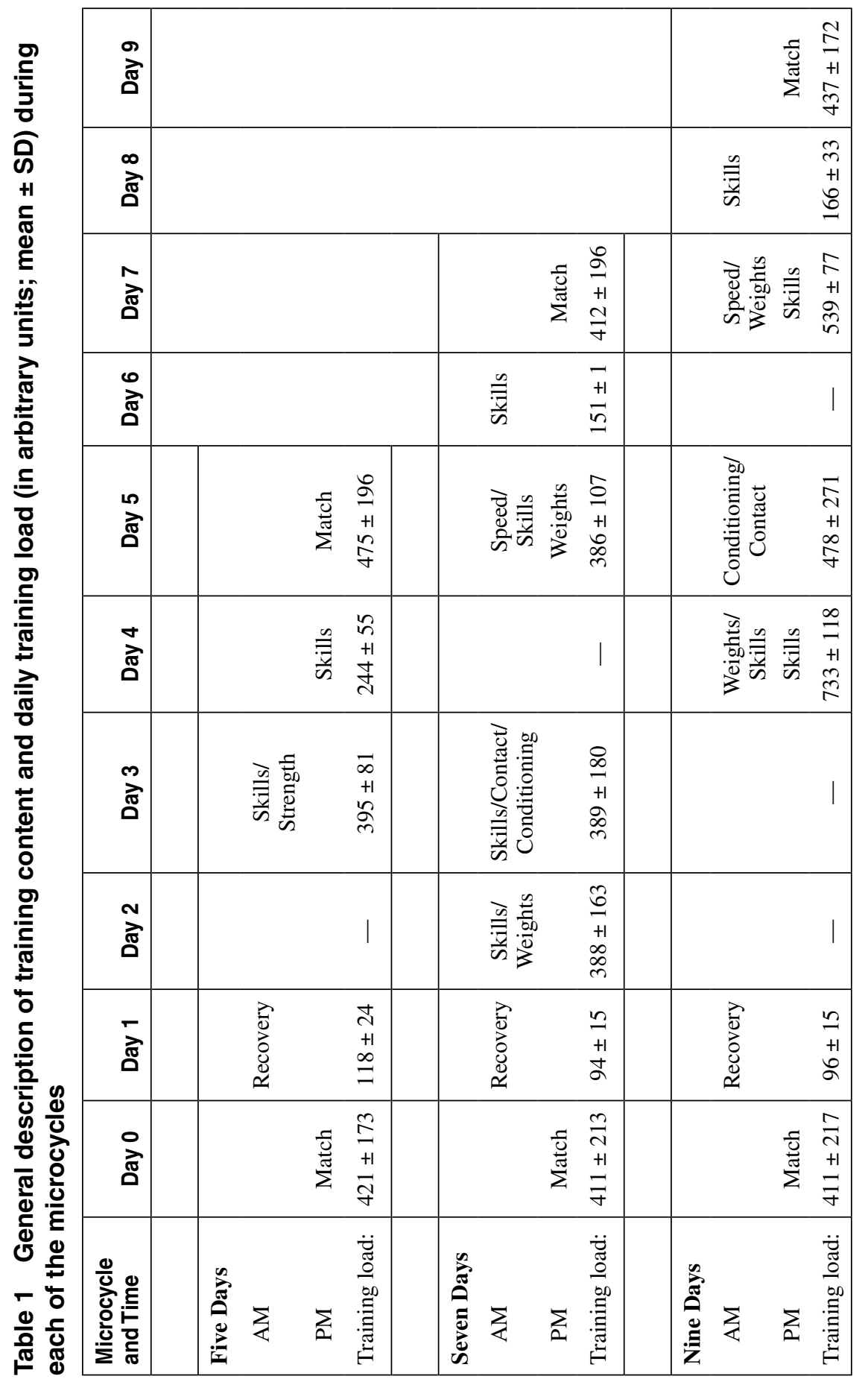



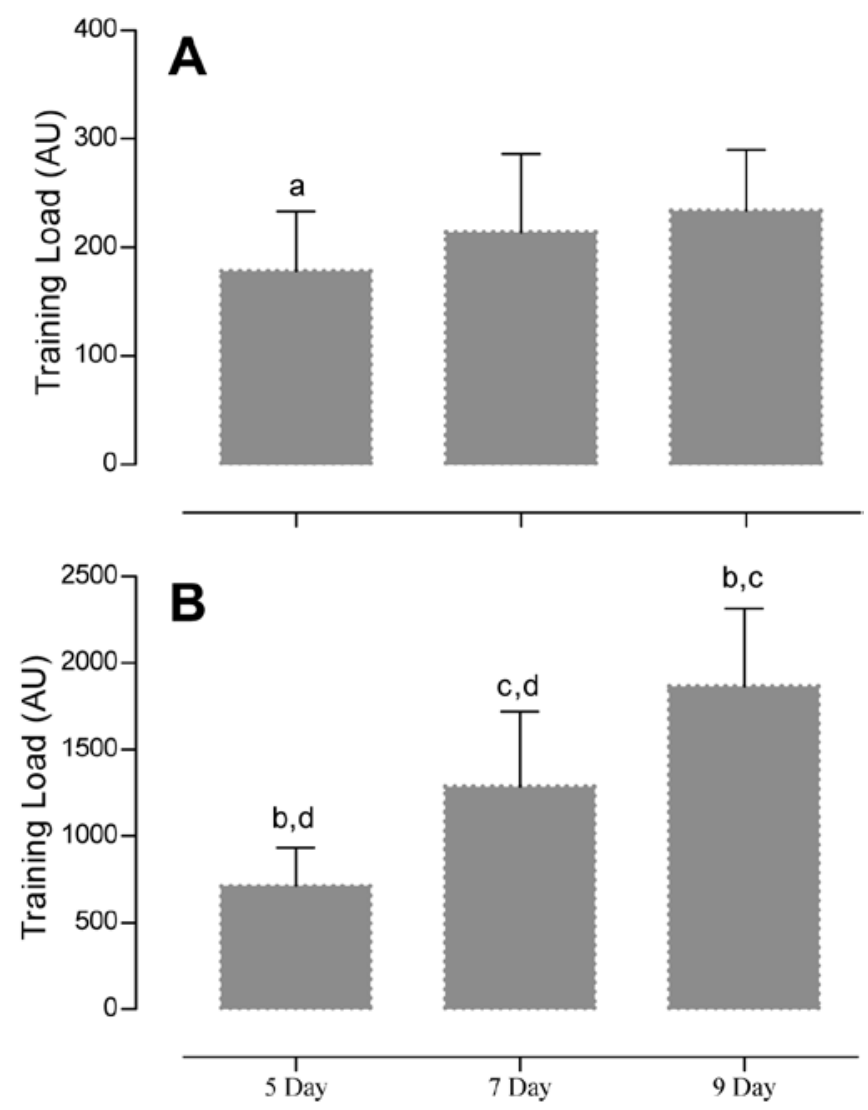

Figure 3 - (A) Daily training load for the different between-match microcycles. (B) Total training load during the different between-match microcycles (all mean $\pm \mathrm{SD}$ ). ${ }^{\text {a Different }}$ from $9 \mathrm{~d}$ and $7 \mathrm{~d}$ microcycles. ${ }^{b}$ Different from $7 \mathrm{~d}$ microcycle. ${ }^{c}$ Different from $5 \mathrm{~d}$ microcycle. ${ }^{\mathrm{d} D i f f e r e n t}$ from $9 \mathrm{~d}$ microcycle (all $P<.05$ ).

$7 \mathrm{~d}(P<.001, d=0.69)$ microcycles and significantly higher overall training load in the $7 \mathrm{~d}$ microcycle when compared with the $5 \mathrm{~d}$ microcycle $(P<.001, d=0.81)$. The mean weekly training load during the $6 \mathrm{wk}$ before testing was significantly lower in the $7 \mathrm{~d}$ microcycle $(1309 \pm 436 \mathrm{AU})$ compared with the 5- $(1704 \pm 419$ $\mathrm{AU})$ and 9 day $(1862 \pm 552 \mathrm{AU})$ microcycles $(P<.02)$.

Figure 4A shows the time course of change of $\mathrm{CMJ}_{\mathrm{FT}}$ measures. Baseline $\mathrm{CMJ}_{\mathrm{FT}}$ values were significantly higher than day $1(P<.001, d=1.67)$ and the day before the match at the end of the training microcycle $(P<.05, d=1.12)$. Baseline $\mathrm{CMJ}_{\mathrm{FT}}$ also tended to be higher than day 4 measures with values approaching significance $(P=.08, d=0.96)$. Day $1 \mathrm{CMJ}_{\mathrm{FT}}$ measures were significantly lower than day $4(P$ $<.01, d=-1.06)$ and the day before the match at the end of the training microcycle $(P<.05, d=1.06)$. 
The $\mathrm{CMJ}_{\text {RelP }}$ was significantly lower overall in the $7 \mathrm{~d}$ microcycle when compared with the $9 \mathrm{~d}$ microcycle $(P<.05, d=-0.94)$ and baseline $(P<.05, d=$ -0.38) (Figure 4B). Furthermore, $\mathrm{CMJ}_{\text {RelP }}$ tended to be reduced on day 4 in the $7 \mathrm{~d}$ microcycle, compared with day 4 in the $9 \mathrm{~d}$ microcycle $(P=.06, d=-1.21)$. The $\mathrm{CMJ}_{\text {RelP }}$ at the end of each microcycle tended to be reduced in the $7 \mathrm{~d}$ compared with the $9 \mathrm{~d}$ microcycle, although differences were not significant, a moderate effect size observed $(d=-0.76)$. There were no significant changes in body mass between the Baseline $(101.9 \pm 8.4 \mathrm{~kg}), 5 \mathrm{~d}(103.3 \pm 7.3 \mathrm{~kg}), 7 \mathrm{~d}(105.1 \pm 7.8 \mathrm{~kg})$, and $9 \mathrm{~d}(101.3 \pm 9.6 \mathrm{~kg})$ microcycles $(P=.55)$.
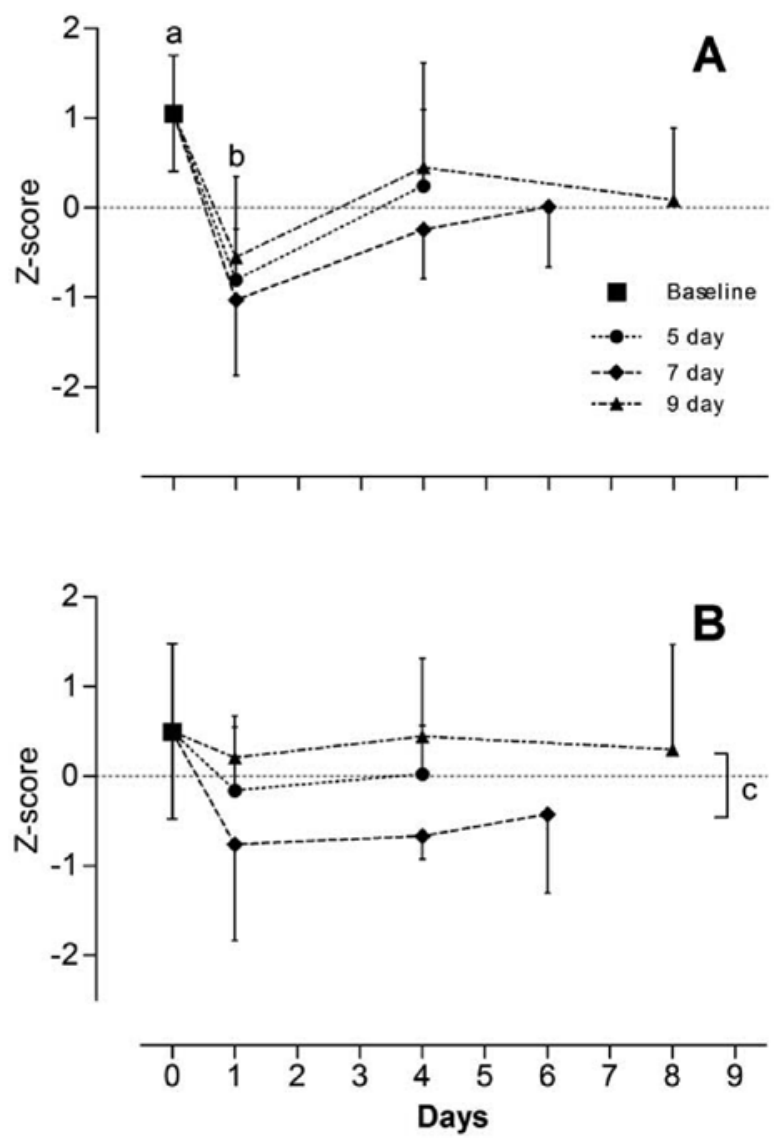

Figure 4 - (A) CMJ flight time for the different between-match microcycles. (B) CMJ relative power the different between-match microcycles. ${ }^{a}$ Denotes significantly different from day 1 and day before following match with all microcycles combined. ${ }^{b}$ Denotes significantly different from day 4 and day before following match with all microcycles combined. ${ }^{c}$ Different between the 7 and $9 \mathrm{~d}$ microcycles, all mean \pm SD. 
Figure 5A show that fatigue levels were significantly worse $1 \mathrm{~d}$ following the match for each training cycle $(P<.01, d=-1.65)$. Fatigue levels tended to be lower at day 2 postmatch from prematch levels in the $7 \mathrm{~d}$ week $(P=.13, d$ $=-1.42)$, and were significantly reduced in the $9 \mathrm{~d}$ microcycle $(P<.001, d=$ $-1.75)$. Fatigue levels returned to near prematch values day 4 in all three experimental weeks. On day 6 in the $9 \mathrm{~d}$ microcycle the fatigue levels were significantly lower $(P<.05, d=-1.31)$ than the following match day values in this week. Significantly lower fatigue levels were reported in the $5 \mathrm{~d}$ week when compared with both the $7 \mathrm{~d}(P<.01, d=0.45)$ and the $9 \mathrm{~d}(P<.01, d=0.36)$ microcycles. Fatigue levels on day 2 following the match were significantly less on the $5 \mathrm{~d}$ week when compared with $7 \mathrm{~d}$ week $(P<.05, d=1.27)$ and the $9 \mathrm{~d}$ week $(P$ $<.01, d=1.67)$. Subjects also tended to exhibit more fatigue on the following match day in the $7 \mathrm{~d}$ microcycle as compared with the $9 \mathrm{~d}$ microcycle, with a moderate effect size $(d=-0.67)$.

Figure 5B shows that overall well-being was significantly reduced at $1 \mathrm{~d}$ postmatch for all microcycles $(P<.01, d=-1.64)$ and remained significantly reduced $2 \mathrm{~d}$ following the match in the $7 \mathrm{~d}(P<.05, d=-1.53)$ and $9 \mathrm{~d}(P<.01, d$ $=-0.18)$ microcycles. Overall well-being measured $2 \mathrm{~d}$ following the match was significantly higher in the $5 \mathrm{~d}$ microcycle compared with the $7 \mathrm{~d}(P<.05, d=1.36)$ and $9 \mathrm{~d}$ microcycle $(P<.01, d=1.66)$. Overall well-being was also significantly higher on the $5 \mathrm{~d}$ microcycle when compared with the $7 \mathrm{~d}(P<.05, d=0.34)$ and $9 \mathrm{~d}(P<.01, d=0.36)$ microcycles.

Figure 5C shows the changes in general muscle soreness during each of the different training microcycles. Overall, players endured less muscle soreness (higher mean values) in the $5 \mathrm{~d}$ microcycle compared with both the $7 \mathrm{~d}(P<.01$, $d=1.46)$ and $9 \mathrm{~d}(P<.05, d=1.56)$ microcycles. General muscle soreness was increased (decreased scores), compared with prematch values, $1 \mathrm{~d}$ postmatch in $5 \mathrm{~d}(P<.01, d=-1.57)$ and $9 \mathrm{~d}(P<.01, d=-1.36)$ experimental microcycles. General muscle soreness also tended to increase $1 \mathrm{~d}$ postmatch in the $7 \mathrm{~d}$ microcycle with values approaching significance $(P=.07, d=-1.26)$. This remained elevated for $2 \mathrm{~d}$ postmatch in the $7 \mathrm{~d}$ microcycle $(P<.05, d=-1.44)$ and also tended to remain elevated in the $9 \mathrm{~d}$ microcycle with values approaching significance $(P=.07, d=-1.44)$. In the $5 \mathrm{~d}$ microcycle general muscle soreness had returned to prematch values on day 2 and was significantly less when compared with the $7 \mathrm{~d}(P<.01, d=1.46)$ and $9 \mathrm{~d}(P \leq .05, d=1.56)$ microcycles on this day. General muscle soreness values returned to prematch values after $4 \mathrm{~d}$ in all experimental microcycles. However, these general muscle soreness tended to increase $6 \mathrm{~d}$ postmatch in the $9 \mathrm{~d}$ microcycle, with values approaching significance $(P=.07, d=-1.36)$.

Figure 6A shows the time course of change of cortisol, testosterone and T:C ratio over the three different in-season microcycles. Day 4 cortisol measures in the 9 day and $7 \mathrm{~d}$ microcycles were significantly higher than game day $(P<.01, d=0.60)$ and tended to be higher than day 1 measures with values approaching significance $(P=.07, d=0.69)$. Cortisol concentrations on day 4 tended to be lower in the 5 $\mathrm{d}$ microcycle when compared with the $9 \mathrm{~d}(d=-0.51)$ and $7 \mathrm{~d}$ microcycles $(d=$ $-0.71)$. No differences were found in testosterone or $\mathrm{T}: \mathrm{C}$ ratio within microcycles or between experimental microcycles. 

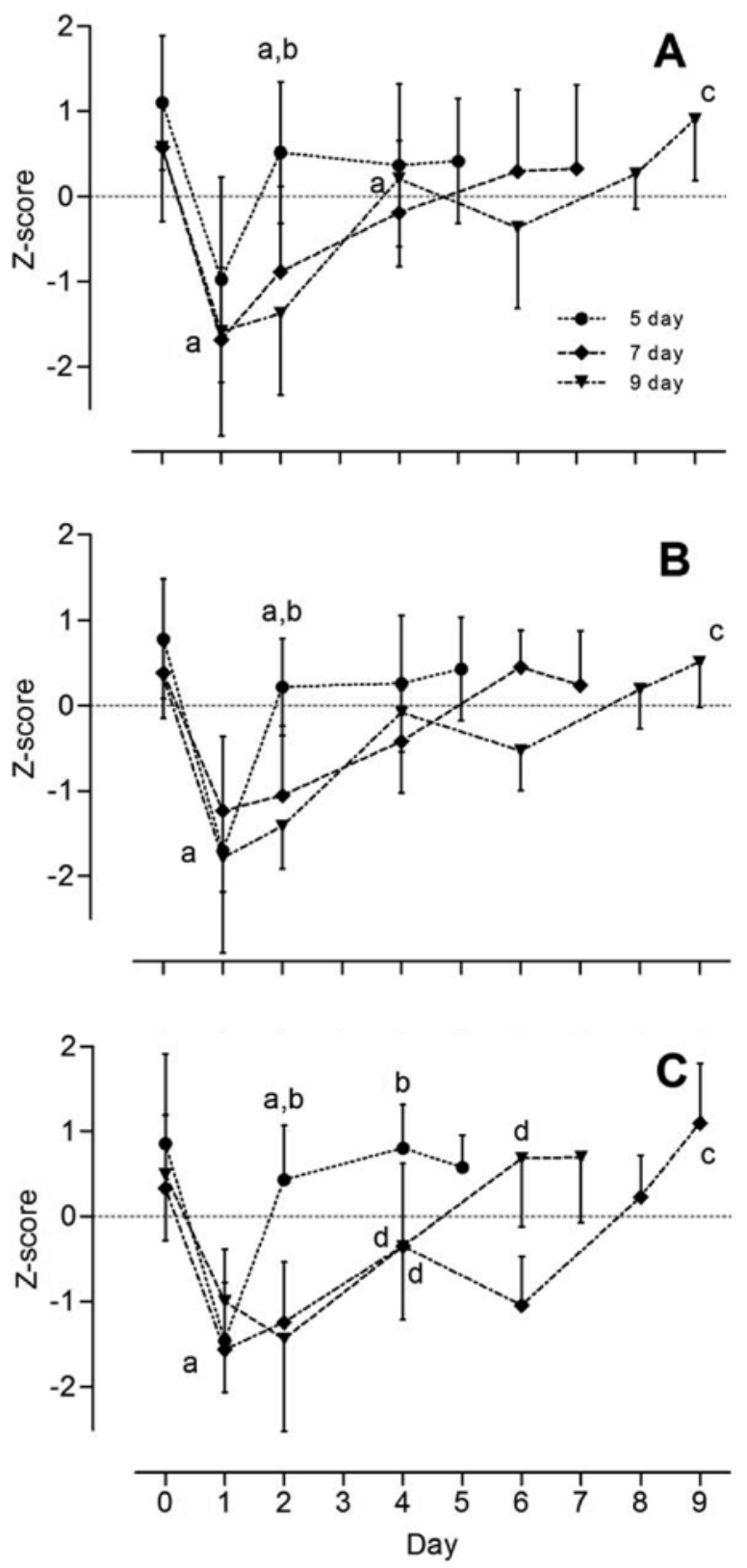

Figure 5 - (A) Fatigue during the different between-match microcycles. (B) Overall WB during the different between-match microcycles. (C) General muscle soreness during the different between-match microcycles (all mean $\pm \mathrm{SD}$ ). ${ }^{\mathrm{a}}$ Different from previous measure for all microcycles. ${ }^{b}$ Different from the 7 and $9 \mathrm{~d}$ microcycles. ${ }^{\mathrm{c}}$ Different from day $6 .{ }^{\mathrm{d}}$ Different from previous measure in the same microcycle (all $P<.05$ ). 

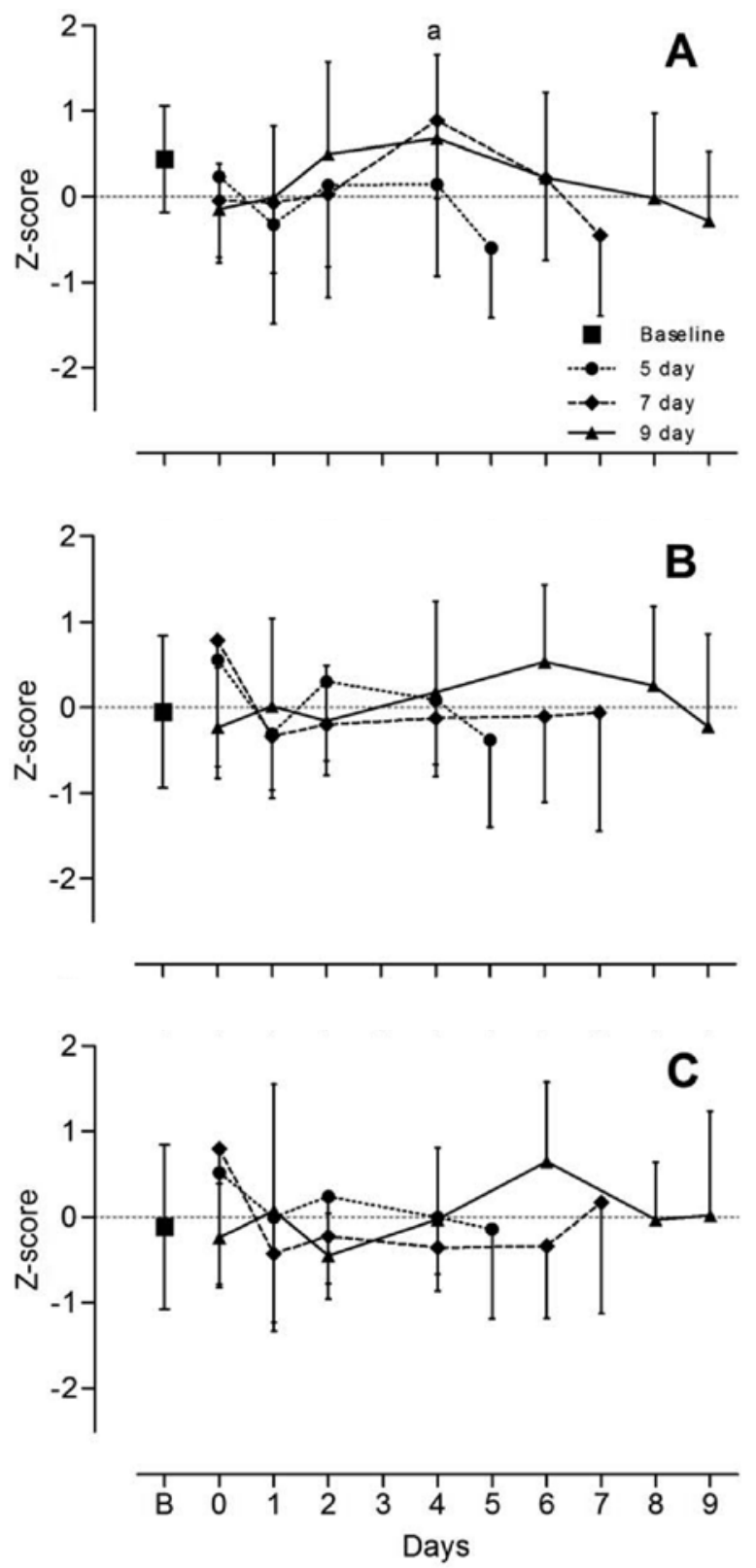

Figure 6 - (A) Cortisol during the different between-match microcycles. (B) Testosterone during the different between-match microcycles. (C) Testosterone-to-cortisol ratio during

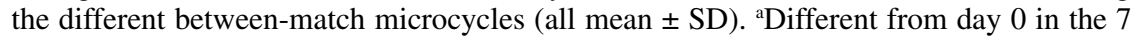
$\mathrm{d}$ and $9 \mathrm{~d}$ microcycles. 


\section{Discussion}

The purpose of this study was to examine the time course of change in neuromuscular, psychological and physiological markers of fatigue following a professional rugby league match. An additional purpose was to distinguish any differences in the recovery of these athletes over different length between-match microcycles. Results showed that CMJ performance is reduced postmatch but returns to its highest in-season levels $4 \mathrm{~d}$ postmatch. Results also show that the psychological variables can detect changes in fatigue and muscle soreness. These findings suggest that regular analyses of both CMJs and psychological questionnaires are useful tools in monitoring in-season fatigue in professional rugby league players.

The training loads completed in this study were slightly lower than previous research examining a professional rugby league team competing in the same competition as the club in this study. ${ }^{4}$ In the current study, there was a lower daily training load in the $5 \mathrm{~d}$ microcycle compared with the $7 \mathrm{~d}$ and $9 \mathrm{~d}$ microcycles. This reduction in load was most likely due to the coaching staff focus on optimizing recovery by reducing the physical training when a shorter recovery period was available. Interestingly, the mean daily training load in the $7 \mathrm{~d}$ and $9 \mathrm{~d}$ weeks were not significantly different (see Figure 2). Despite this, each of the training microcycles elicited subtly different recovery profiles in the neuromuscular and psychological measures. These results show that careful titration of training load is important for neuromuscular and perceptual recovery from professional rugby league match play.

The $\mathrm{CMJ}_{\mathrm{FT}}$ was significantly reduced in the $24 \mathrm{~h}$ following the first match in each training cycle. These results agree with Cormack et al, ${ }^{7}$ who showed that both $\mathrm{CMJ}_{\mathrm{FT}}$ was reduced in the days following competition. The present findings also support other studies which have shown CMJ performance to decrease following strenuous athletic competition ${ }^{7,10,18}$ and intensified training. ${ }^{19}$ Paradoxically, there were no significant within microcycle changes in $\mathrm{CMJ}_{\text {RelP }}$ measurements following the initial postmatch reduction (from preseason levels) for any of the training microcycles. However, although no changes were observed during the training microcycles, the power measurements showed differences between each of the microcycles. For example, $\mathrm{CMJ}_{\mathrm{RelP}}$ was significantly reduced throughout the $7 \mathrm{~d}$ microcycle when compared with the $9 \mathrm{~d}$ microcycle. These results support recent theories that suggest power measures might be more useful in monitoring long term, low frequency fatigue (LFF). ${ }^{20}$ On the basis of these findings we suggest that future studies examine the CMJ power variables that may be a useful for monitoring LFF in rugby league players.

A notable finding in this study was that the $\mathrm{CMJ}_{\text {RelP }}$ measurements in the $7 \mathrm{~d}$ microcycle were consistently lower than the $9 \mathrm{~d}$ microcycle. This finding, coupled with the high relative training load in the $7 \mathrm{~d}$ microcycle, suggests that the players had greater neuromuscular fatigue, most likely as a result of an inappropriate training dose. The high training dose within the $7 \mathrm{~d}$ microcycle is likely to have affected neuromuscular status; however, it is also possible that inappropriate training in the weeks before this training microcycle or subtle changes in training content during each of the microcycles may have had an effect on the neuromuscular status of the athletes. In this study the mean weekly training for the $6 \mathrm{wk}$ before the testing week was lowest for the $7 \mathrm{~d}$ microcycle and highest in the $9 \mathrm{~d}$ microcycles, suggesting cumulative training load in the weeks before each testing period was 
not responsible for the acute changes in $\mathrm{CMJ}_{\text {RelP }}$. Collectively, however, the present and previous ${ }^{5,7}$ results indicate that neuromuscular fatigue in football players can be monitored via CMJ variables that include flight time and power. It is possible that these measures may be used to assess the time course of recovery following a match, the neuromuscular recovery between matches, and LFF that may occur during a training season. Future studies should examine the CMJ variables, throughout different training microcycles, under more strictly controlled experimental microcycles.

Similar to the neuromuscular performance measures, there was an increase in the player's fatigue and muscle soreness and poorer overall well-being following each match which improved in the days following. In addition, the player's perception of overall well-being returned to near baseline levels within $4 \mathrm{~d}$ following the match in each training cycle. Previous research has shown changes in an athlete's perception of well-being and fatigue often occur concurrently with maladaptive training. ${ }^{3,13,21-24}$ In this study, there was an increase in fatigue in the $7 \mathrm{~d}$ microcycle, when relative daily training load was greater, and subtle increases in fatigue were detected in the days following heavy training within a microcycle. For example, there was an increase in fatigue levels on day 6 in the $9 \mathrm{~d}$ microcycle following 2 $\mathrm{d}$ of heavy training on days 4 and 5 .

General muscle soreness measures also showed important changes within each of the different training microcycles and may have important practical implications. The return to baseline values in general muscle soreness during the $5 \mathrm{~d}$ microcycle was accelerated compared the 7 and $9 \mathrm{~d}$ microcycles. This rapid recovery occurred despite the same training being completed on day 1 postmatch in all three experimental weeks. This suggests that optimal recovery of perception of general muscle soreness following a match is affected by many variables such as adaptation to previous training, the extent of damage that occurred during match play and is not limited to the type and amount of training completed in the days following competition. Interestingly, a similar pattern also occurred with the Fatigue and overall well-being scores providing further support for this simple psychometric tool for assessing recovery from training and matches in rugby league.

In the current study, changes in salivary cortisol and testosterone were monitored to examine alterations in the player's anabolic/catabolic balance during the different training microcycles. The testosterone measures were highly variable and there were no changes within or between each of the different training microcycles. Due to the variable nature of testosterone, the T:C ratio was also highly variable and did not appear to be influenced by changes in training loads and/or competition. These results agree with Cormack et $\mathrm{al}^{7}$ who reported that testosterone or $\mathrm{T}: \mathrm{C}$ ratio did not change in the days following a preseason ARF match.

There were also large variations in cortisol during the study; however, there was a small postmatch reduction for 24 to $48 \mathrm{~h}$ and then an increase until $4 \mathrm{~d}$ following the match in each microcycle. In contrast to the present results, one previous study has shown salivary cortisol to increase $24 \mathrm{~h}$ after an ARF match. ${ }^{7}$ The current finding of a reduced cortisol for $24 \mathrm{~h}$ following a match agrees with previous research that reported small decreases in morning cortisol levels in the days following an international rugby union match ${ }^{14}$ and a $3 \mathrm{~d}$ wrestling competition. ${ }^{25}$ In the current study, there was also a tendency for lower cortisol response in the $5 \mathrm{~d}$ microcycle compared with the $7 \mathrm{~d}$ and $9 \mathrm{~d}$ microcycles. The lower mean daily training load in this microcycle is the most probable explanation for the lower stress response. No 
other study has reported salivary cortisol to be elevated to its highest values several days following a match. In contrast to these previous results, and the results from the current study, Cormack et $\mathrm{al}^{7}$ found salivary cortisol to increase to its highest recorded values $1 \mathrm{~d}$ after an ARF match followed by a decline the lowest values following $4 \mathrm{~d}$. The differences in research design between the present and previous studies ${ }^{7}$ makes accurate interpretation of results difficult.

Many physiological and psychological factors can influence cortisol response. Clearly a limitation of this study, from a research design perspective, is the uncontrolled training environment in which the data are collected. Although this makes interpretation of changes in variables difficult, there is a high level of ecological validity in the findings. More applied training/recovery interventions in the field, with high level athletes are required so that factors affecting athlete performance in the competitive environment are better understood.

\section{Summary}

The present investigation showed that neuromuscular and perceptual fatigue measures are reduced $24 \mathrm{~h}$ following a professional rugby league match and can return to baseline values within $4 \mathrm{~d}$ of competition. Current results also show that the placement of training within each between match microcycle is important for appropriate recovery from rugby league matches. Perception of fatigue and muscle soreness and CMJ performance were affected by stress of professional rugby league match play and also the training content within each microcycle. The $\mathrm{CMJ}_{\mathrm{FT}}$ appeared to be useful for assessing acute fatigue caused by a match, while the $\mathrm{CMJ}_{\text {RelP }}$ was different between each of the microcycles suggesting that it may be suited to monitor for accumulated, LFF fatigue. Psychometric measurements taken in this study were sensitive to acute fatigue during each training week, with subtle changes in training load eliciting changes in the player's perception of muscle soreness and general fatigue. In addition, the perceptual fatigue responses were also consistently lower when a high daily training load was performed throughout a training microcycle. Collectively, these results suggest that small changes to relative in-season training load, within professional rugby league, may have a significant impact on player's neuromuscular and psychometric fatigue status. The current study shows that both CMJs and psychological questionnaires can be useful for monitoring fatigue in team sports such as rugby league. Specifically, these measures can show unique recovery profiles that appear to follow training load and this makes them useful for assessing player recovery between games in professional rugby league.

\section{Practical Applications}

This study was conducted in a real training environment with top level professional rugby league players which allows for several important practical findings to be made. The current findings are important as they show that inappropriate training loads within a between-match microcycle can negatively impact on neuromuscular status, perception of fatigue and muscle soreness. Psychological questionnaires provide a simple and cost-effective monitoring tool for coaches and should be implemented on a regular basis throughout a team sport season. We suggest that coaches and scientists can flag values that are greater than one Z-score from their 
individual mean for further follow-up. In agreement with recent studies, ${ }^{5,7}$ we also suggest that coaches should perform weekly analyses of CMJ power measurements, and use these results in conjunction with psychometric variables to adjust between match training loads so that performance can be optimized.

\section{Acknowledgments}

The authors would like to thank the players and management of the South Sydney Rabbitohs Rugby League Football Club for their enthusiastic participation in this study. Special thanks are extended to Errol Allcott and Grant Duthie for their assistance with this project. This research was supported by a grant from the South Sydney Rabbitohs Rugby League Football Club.

\section{References}

1. Smith DJ. A framework for understanding the training process leading to elite performance. Sports Med. 2003;33(15):1103-1126.

2. Rowbottom DG. Periodization of training. In: Garret J, W.E., Kirkendall DT, eds. Exercise and Sport Science. Philadelphia: Lippincott, Williams and Wilkins; 2000:499-514.

3. Coutts AJ, Reaburn PRJ. Monitoring changes in stress and recovery during overreaching in rugby league players. Percept Mot Skills. 2008;106(3):904-916.

4. Coutts AJ, Charmari K, Rampinini E, Impellizzeri FM. Contrôle et suivi de l'entraînement : périodisationet charges d'entraînement. In: Dellal A, ed. De L囚entraînement à la Performance en Football. Paris, France: De Boeck Universite; 2008:242-263.

5. Cormack SJ, Newton RU, McGuigan MR, Cormie P. Neuromuscular and endocrine responses of elite players during an Australian rules football season. Int J Sports Physiol Perform. 2008;3(4):439-453.

6. Coutts A, Reaburn P, Piva TJ, Murphy A. Changes in selected biochemical, muscular strength, power, and endurance measures during deliberate overreaching and tapering in rugby league players. Int J Sports Med. 2007;28(2):116-124.

7. Cormack SJ, Newton RU, McGuigan MR. Neuromuscular and endocrine responses of elite players to an Australian Rules Football match. Int J Sports Physiol Perform. 2008;3(3):359-374.

8. Cormack SJ, Newton RU, McGuigan MR, Doyle TLA. Reliability of measures obtained during single and repeated countermovement jumps. Int J Sports Physiol Perform. 2008;3(2):131-144.

9. Foster C, Florhaug JA, Franklin J, et al. A new approach to monitoring exercise training. J Strength Cond Res. 2001;15(1):109-115.

10. Hoffman JR, Nusse V, Kang J. The effect of an intercollegiate soccer game on maximal power performance. Can J Appl Physiol. 2003;28(6):807-817.

11. Coutts AJ, Sirotic AC, Knowles H, Catterick C. Monitoring Training Loads in Professional Rugby League. In: Reilly T, Korkusuz F, eds. Science and Football VI. London, UK: Routledge; 2008:1-6.

12. Coutts AJ, Reaburn P, Piva TJ, Rowsell GJ. Monitoring for overreaching in rugby league players. Eur J Appl Physiol. 2007;99(3):313-324.

13. Coutts AJ, Slattery KM, Wallace LK. Practical tests for monitoring performance, fatigue and recovery in triathletes. J Sci Med Sport. 2007;10(6):372-381.

14. Elloumi M, Maso F, Michaux O, Robert A, Lac G. Behaviour of saliva cortisol [C], testosterone $[\mathrm{T}]$ and the $\mathrm{T} / \mathrm{C}$ ratio during a rugby match and during the post-competition recovery days. Eur J Appl Physiol. 2003;90(1-2):23-28. 
15. Filaire E, Bernain X, Sagnol M, Lac G. Preliminary results on mood state, salivary testosterone:cortisol ratio and team performance in a professional soccer team. Eur J Appl Physiol. 2001;86(2):179-184.

16. Filaire E, Lac G, Pequignot JM. Biological, hormonal, and psychological parameters in professional soccer players throughout a competitive season. Percept Mot Skills. 2003;97(3 Pt 2):1061-1072.

17. Hooper SL, Mackinnon LT. Monitoring overtraining in athletes: recommendations. Sports Med. 1995;20(5):321-327.

18. Petersen K, Hansen CB, Aagaard P, Madsen K. Muscle mechanical characteristics in fatigue and recovery from a marathon race in highly trained runners. Eur J Appl Physiol. 2007;101(3):385-396.

19. Minetto MA, Lanfranco F, Tibaudi A, Baldi M, Termine A, Ghigo E. Changes in awakening cortisol response and midnight salivary cortisol are sensitive markers of strenuous training-induced fatigue. J Endocrinol Invest. 2008;31(1):16-24.

20. Fowles JR. Technical Issues in Quantifying Low-Frequency Fatigue in Athletes. Int J Sports Physiol Perform. 2006;1:169-171.

21. Lambert MI, Borresen J. A theoretical basis of monitoring fatigue: A practical approach for coaches. Int J Sports Sci Coaching. 2006;1(4):371-387.

22. Morgan WP, Brown DR, Raglin JS, O'Connor PJ, Ellickson KA. Psychological monitoring of overtraining and staleness. Br J Sports Med. 1987;21(3):107-114.

23. WP, Costill DL, Flynn MG, Raglin JS, O'Connor PJ. Mood disturbance following increased training in swimmers. Med Sci Sports Exerc. 1988;20(4):408-414.

24. Urhausen A, Gabriel HHW, Brukner F, Kindermann W. Effects of two training phases of different intensities on exercise-induced hormonal response and psychological parameters in endurance athletes. Int J Sports Med. 1998;19:s43-s44.

25. Passelergue $P$, Lac G. Saliva cortisol, testosterone and T/C ratio variations during a wrestling competition and during the post-competitive recovery period. Int J Sports Med. 1999;20(2):109-113. 
Copyright of International Journal of Sports Physiology \& Performance is the property of Human Kinetics Publishers, Inc. and its content may not be copied or emailed to multiple sites or posted to a listserv without the copyright holder's express written permission. However, users may print, download, or email articles for individual use. 